\title{
Characteristics of Delamination Factor and Surface Roughness by Drilling Condition for Glass Fiber Reinforced Plastic Composites
}

\author{
Ok-Kyu Lee*, Dae-Keon Ahn**, Jin-Ho Choi**†, Jin-Hwe Kweon***
}

\begin{abstract}
Characteristics of delamination factor and surface roughness by drilling condition for glass fiber reinforced plastic (GFRP) composites were investigated in this paper. An expression to quantify the delamination factor was induced by using image pixels of the entry and the experimental drilling was accomplished by fabricating several GFRP specimens in condition of minimizing the effect of vibration and heat. A method for measuring 6 points average surface roughness was applied to acquire the more reliable roughness values. The experimental results showed that the delamination factor was decreased as the feed rate was increased and it was also slightly decreased as the cutting speed was increased. Also, it was investigated that the surface roughness at inner surface of drilled holes was increased as the feed rate was increased, whereas the roughness values were not affected by the cutting speed variation.
\end{abstract}

초 록: 본 논문에서는 유리섬유복합재(glass fiber reinforced plastic composites)의 드릴가공조건변화에 따른 박리 지수와 표면조도 특성이 분석되었다. 드릴 가공된 홀의 입출구에서 이미지 픽셀을 이용하여 박리지수를 산출할 수 있는 관계식이 유도되었으며, 복합재 시편을 제작하여 진동 및 열 영향을 최소화할 수 있는 가공조건에서 드 릴가공을 수행하여 보다 신뢰성 있게 표면조도값을 얻기 위하여 6점평균표면조도측정 방식이 적용되었다. 실험 결과로부터 GFRP 드릴가공에서 박리지수는 이송속도 증가에 감소하고, 절삭속도 증가에도 미세하게 감소함을 볼 수 있었다. 또한 드릴가공된 홀 내부에서 표면조도는 이송속도가 증가할수록 증가하고, 절삭속도 변화에는 영향 을 받지 않음이 파악되었다.

Key Words: 유리섬유(GFRP), 박리(delamination), 드릴가공(drilling), 이송속도(feed rate), 절삭속도(cutting speed), 표면조도(surface roughness)

1. 서 론

섬유 강화 복합재(Fiber reinforced composites)는 우수한 등방성 재료와 비교하여 비강성과 비강도가 높고, 감쇠 및 충격 특성이 우수하기 때문에 항공우주, 수송기계, 무기 등
의 분야에서 그 이용이 점차 증가하고 있으며, 응용 분야 또 한 다변화되고 있다[1]. 이러한 복합재를 이용하여 항공기 동체와 같이 대면적 가공이 요구되거나 특정한 형태의 모 양을 얻기 위하여 일반적으로 체결이 필요하다. 그리고 볼 트나 리벳 등을 이용한 견고한 체결을 위하여 드릴가공

Received 31 October 2013, received in revised form 18 November 2013, accepted 2 December 2013

*한국폴리텍대학 달성캠퍼스 자동화시스템학과

**경상대학교 항공기부품기술연구소

**†경상대학교 기계공학부 항공기부품기술연구소, Corresponding author (E-mail: choi@gnu.ac.kr)

***경상대학교 항공우주시스템공학과 항공기부품기술연구소 
(Drilling)과 같은 추가적인 기계적 가공이 요구된다. 그러 나 이러한 가공으로 인하여 소재표면을 훼손할 수 있고, 더 불어 강도저하나 응력집중과 같은 기계적 결함의 위험성 을 초래할 수 있다.

박리는 복합재 드릴가공에서 관찰되는 주요 훼손 중 하 나며, 이러한 이유로 복합재 이용에서 하나의 중요한 제한 적인 요인이 될 수 있다. 즉, 응력집중이나 미세크랙을 야 기하여 복합재 이용상의 장점을 현저히 줄인다[2]. 따라서 이러한 박리현상을 줄이기 위한 다양한 접근이 시도되었 는데, 우선 주요 절삭 변수와 드릴가공 형태 간에 영향을 가 늠할 수 있는 정량적인 평가방식이 도입되었다[2-5]. 즉, 복 합재 드릴가공시 홀 입구 및 출구에서 박리는 전통적으로 박리지수(Delamination factor) 를 이용하여 홀의 중심으로 부터 크랙(Crack)의 최대길이로써 평가한다. 드릴 가공조 건 변화에 따라 이러한 박리지수의 영향을 분석하기 위한 다양한 접근이 있었는데 대표적인 연구들은 다음과 같다. Chen 등은 CFRP 복합재료 드릴가공에서 박리 정도를 쉽게 해석하고 비교할 수 있도록 박리지수 개념을 제안했으며, 드릴가공 동안 박리 발생 유무에 따른 다양한 절삭력 변화 를 실험하였다. 또한, CFRP 드릴가공에서 절삭력 변화에 대한 공구형상 및 드릴가공조건의 효과를 실험적으로 관 찰하였다. 실험결과로부터, 공구형상이나 드릴가공조건에 따라 박리를 최소화 할 수 있음을 제시하였다. 또한, 박리 지수와 관련하여 드릴가공조건과 공구마모 효과의 연관성 에 대한 연구가 진행되었다[3]. Mohan 등은 GFRP 드릴가 공에서 박리 출현을 최소화시키기 위하여 다구찌(Taguchi) 기법을 이용하여 최적절삭조건을 결정하는 방안을 제시하 였다. 이송속도, 절삭속도 그리고 시편두께가 박리효과에 큰 영향이 있음을 보였고, 전반적으로 높은 절삭속도와 낮 은 이송속도가 박리를 최소화할 수 있으며, 더 우수한 표면 조도와 보다 긴 공구수명을 유도할 수 있다는 분석결과를 제시하였다[4]. Ramesh 등은 비적층(Nonlaminated) GFRP 의 드릴가공에서 ANOVA 분석을 이용하여 이송속도, 절삭 속도, 토크와 박리 등의 인자에 대한 상대적인 영향을 분석 하였다. 실험 및 분석결과, 절삭속도에 비례하여 박리는 증 가하며, 이송속도가 증가할수록 박리로 인한 표면 훼손은 적음을 보였다[5]. 한편, Zitoune 등은 CFRP 및 알루미늄 적 층 소재의 드릴가공에서 드릴직경, 주축회전속도, 이송속 도, 토크, 표면조도 등의 영향을 분석하였다. 또한 가공조 건 변화에 따른 칩(Chip) 형태를 분석하였다. 이들은 가공 홀 내부의 표면조도는 이송속도가 증가할수록 큰 값을 가 지고, 절삭속도에 비례하여 나빠짐을 보였다[6]. 이처럼 기 존 연구들로부터 섬유강화복합재의 경우 복합재 종류, 이 송속도, 절삭속도 등 드릴가공조건에 따라 박리 및 가공홀 내부 표면조도에 미치는 특성은 매우 다양함을 볼 수 있다.

본 연구에서는 유리섬유복합재(Glass fiber reinforced plastic composites)의 드릴가공조건변화에 따른 홀 입구 및
출구에서 박리지수와 가공홀 내부의 표면조도 특성을 분 석하였다. 보다 신뢰성 있게 박리지름을 구하기 위하여 확 대된 디지털 이미지로부터 픽셀개수를 이용하여 박리지수 를 산출할 수 있는 관계식을 유도하였으며, 복합재 시편을 제작하여 진동 및 열 영향을 최소화할 수 있는 가공조건에 서 각 실험조건에 따라 드릴가공을 수행하였다. 또한, 박리 지수는 유도된 식을 적용하여 산출하였고, 표면조도측정은 정확도를 높이기 위하여 6점평균표면조도측정 방식을 적 용하였다.

\section{2. 박리영역 정량화 및 드릴가공}

\section{1 박리영역 정량화}

Fig. 1은 복합재 드릴가공시 홀 입구 및 출구에서 일반적 으로 발생하는 훼손영역(Damage zone)에 대한 개념도를 보 여주고 있다. 훼손영역 정량화를 위하여 가장 널리 사용되 는 수식은 식 (1)이며, 박리지수(Delamination factor)라 한 다. 즉, 박리지수 $\left(\mathrm{F}_{\mathrm{d}}\right)$ 는 가공된 홀의 지름 $\left(\mathrm{D}_{\mathrm{o}}\right)$ 에 대한 훼손 영역 최대지름 $\left(\mathrm{D}_{\max }\right)$ 의 비율이다.

$$
F_{d}=\frac{D_{\max }}{D_{o}}
$$

본 연구에서 박리영역을 정량화하기 위하여 홀 주변의 훼손영역을 확대사진으로 디지털이미지(Digital image)를 생성하고, 이미지 데이터를 픽셀 (Pixel) 단위로 처리하여 계산에 이용한다. 훼손영역에 대한 이미지처리 과정이 완 료되면, 이미지상으로 나타나는 직경의 길이는 픽셀의 개 수에 비례하므로 훼손영역최대지름 $\left(\mathrm{D}_{\max }\right)$ 은 아래에 주어진 식 (2)와 같이 유도된다.

$$
D_{\max }=D_{o} \frac{N_{p}\left(D_{\max }\right)}{N_{p}\left(D_{o}\right)}
$$

여기서, $\mathrm{N}_{\mathrm{p}}\left(\mathrm{D}_{\max }\right)$ 와 $\mathrm{N}_{\mathrm{p}}\left(\mathrm{D}_{\mathrm{o}}\right)$ 는 각각 훼손영역최대지름과 가 공 홀지름에 대한 픽셀의 개수며, 이미지 처리 툴(Image

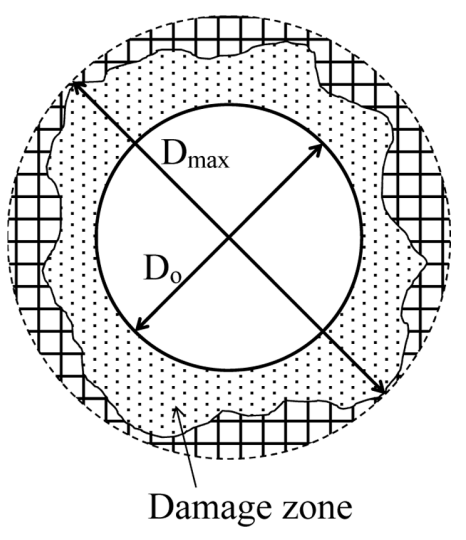

Fig. 1. Schematic diagram of damage zone 
processing tool)에서 얻어진다. 따라서 식 (2)로부터 기존 박 리지수 식 (1)은 다음과 같이 식 (3)로 표현된다.

$$
F_{d}=\frac{N_{p}\left(D_{\max }\right)}{N_{p}\left(D_{o}\right)}
$$

유도된 식으로부터 이미지처리 결과 픽셀개수만 파악되 면 박리지수를 용이하게 산출할 수 있고, 확대된 이미지로 부터 육안이 아닌 디지털적으로 산출할 수 있으므로 보다 신속하고 정교하게 최대직경을 구할 수 있다.

\section{2 드릴가공}

복합재 드릴가공 실험에 사용된 유리섬유 시편의 재료 는 GEP224(4-harness satin weave glass/epoxy prepreg)이며, 시편은 $0.25 \mathrm{~mm}$ 두께의 프리프레그를 적층각도 [0/90]14s 로 적층하여 총 $7 \mathrm{~mm}$ 두께로 제작하였다. 사용된 드릴은 고속도강으로 직경은 $8 \mathrm{~mm}$ 이다. 가공조건 즉 이송속도, 절 삭속도, 가공횟수 변화에 대한 가공면의 특성을 파악하기 위하여 각 가공조건에 따라 한 시편당 총 50 개의 홀을 가공 하였다. 드릴 축방향 이동시 홀의 입구 대비 출구에서 박리 현상을 비슷하게 가질 수 있도록 하부에 별도로 아크릴소 재의 지지대를 장착하였다. 그리고 진동에 의한 영향을 최 소화하기 위하여 Fig. 2 와 같이 시편 가장자리에 바이스를 최대한 밀착시켜 고정시켰다. 또한, 가공횟수 변화에 대한 열의 영향을 최대한 줄이기 위하여 절삭유 공급에 의한 습 식가공으로 드릴 작업을 수행하였다.

가공조건 변화에 대한 박리영역 특성을 세밀하게 분석 하기 위하여 본 논문에서 사용된 가공조건은 각각 다음과 같다. 이송속도 $\mathrm{f}(\mathrm{mm} / \mathrm{rev})$ 는 기준절삭속도 $\mathrm{Vc}=21.31$ 에서 $\mathrm{f}=0.0125$ 부터 $\mathrm{f}=0.40$ 까지 2 배로 증가시켜 6 단계의 변화를 가지며, 절삭속도 $\mathrm{Vc}(\mathrm{m} / \mathrm{min})$ 는 기준이송속도 $\mathrm{f}=0.15$ 에서 $\mathrm{Vc}=10.66,15.08,21.31,30.16,42.65$ 값을 가진다. 한편, 가공 횟수 변화에 따른 특성을 분석하기 위하여 각 시편당 총 50 개의 홀에서 12 개의 홀을 샘플링하여 Fig. 3 에 보이는 화 살표 위치의 홀들을 지정하였다. 이것은 가공으로 인한 진

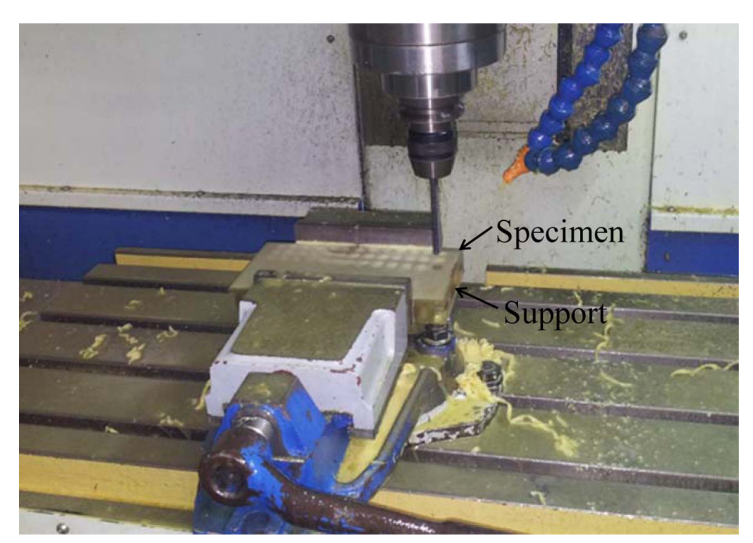

Fig. 2. Experimental drill machining

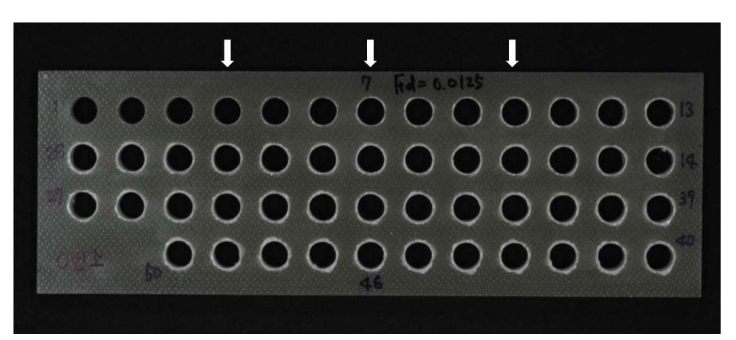

Fig. 3. Measurement holes to quantify delamination factors

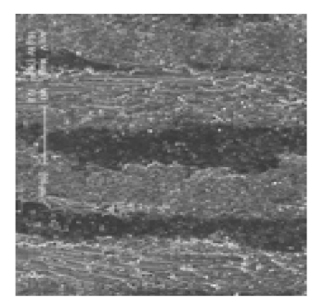

(a) SEM image

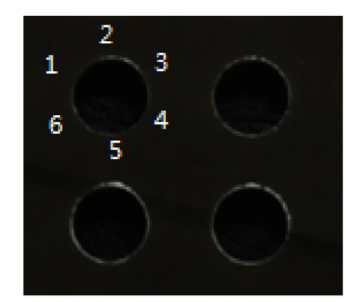

(b) 6 points to measure surface roughness
Fig. 4. Measurement holes to quantify delamination factors

동과 변형 최소화를 목적으로 보다 신뢰할 수 있는 데이트 를 얻기 위함이다. 따라서 측정홀들은 가공진행 순서대로 $4,7,10,17,20,23,30,33,36,43,46,49$ 등의 번호가 부 여된다. 그리고 각 실험조건 별로 가공특성을 분석하기 위 하여 각 시편당 새로운 드릴이 사용되었다.

또한, 가공조건에 대한 표면조도의 변화특성을 다음과 같은 방법으로 분석하였다. Fig. 4는 유리섬유 복합재의 드 릴가공된 홀의 일부와 홀내부 표면의 SEM이미지를 보여 주고 있다. Fig. 4(a)에 보이는 것처럼 가공된 유리섬유 가 닥의 불균일한 형상과 수직방향의 드릴이송에 의한 레진 밀림현상으로 측정위치에 따라 표면조도의 편차가 존재할 수밖에 없음을 알 수 있다. 따라서 본 연구에서는 보다 합 리적으로 표면조도를 얻기 위하여 Fig. 4(b)와 같이 가공홀 의 둘레를 따라 6 곳의 측정위치를 정하여 표면조도를 측정 하고, 이들을 평균하여 최종적인 표면조도값을 얻는 방식 (6점평균표면조도측정)을 적용하였다. 표면조도분포는 1 10 um로 예상하여 ISO규격(ISO 4288:1996)에 따라 기준 길이 $2.5 \mathrm{~mm}$ 에서 총평가 길이는 $12.5 \mathrm{~mm}$ 로 설정하여 측정 되었다.

\section{3. 고찰 및 분석}

유리섬유 복합재의 드릴가공조건에 따라 가공홀 입구 및 출구에서 훼손영역의 특성은 다음과 같이 도출 및 분석되 었다. 이미지 처리툴은 포토샵(PS6.0 Extended)이 사용되었 고, 특성평가 검토는 2 장에서 유도한 박리지수를 이용하여 수행되었다. Table 1 은 본 연구에서 적용된 세부적인 드릴 가공조건을 보여주고 있다. 
Table 1. Test condition, test name and test value

\begin{tabular}{c|c|c}
\hline Test condition & Test name & Value \\
\hline \multirow{4}{*}{$\begin{array}{c}\text { Feed rate } \\
(\mathrm{mm} / \mathrm{rev})\end{array}$} & $\mathrm{F} 1$ & 0.0125 \\
\cline { 2 - 3 } At, Vc $=21.31 \mathrm{~m} / \mathrm{min}$ & $\mathrm{F} 2$ & 0.025 \\
\cline { 2 - 3 } & $\mathrm{F} 3$ & 0.05 \\
\cline { 2 - 3 } & $\mathrm{F} 4$ & 0.1 \\
\cline { 2 - 3 } & $\mathrm{F} 5$ & 0.2 \\
\hline \multirow{4}{*}{$\begin{array}{c}\text { Cutting speed } \\
(\mathrm{m} / \mathrm{min})\end{array}$} & $\mathrm{F} 6$ & 0.4 \\
\cline { 2 - 3 } At, $\mathrm{f}=0.15 \mathrm{~mm} / \mathrm{rev}$ & $\mathrm{V} 1$ & 10.66 \\
\cline { 2 - 3 } & $\mathrm{V} 2$ & 15.08 \\
\cline { 2 - 3 } & $\mathrm{V} 3$ & 21.31 \\
\cline { 2 - 3 } & $\mathrm{V} 4$ & 30.16 \\
\hline
\end{tabular}

Table 2. Pixels and delamination factor by tests

\begin{tabular}{c|c|c|c}
\hline Hole No. & $N_{p}\left(D_{o}\right)$ & $N_{p}\left(D_{\max }\right)$ & $F_{d}$ \\
\hline H4 & 118 & 133 & 1.13 \\
\hline H7 & 117 & 136 & 1.16 \\
\hline H10 & 118 & 135 & 1.14 \\
\hline H17 & 117 & 141 & 1.20 \\
\hline H20 & 117 & 144 & 1.23 \\
\hline H23 & 118 & 144 & 1.22 \\
\hline H30 & 117 & 142 & 1.21 \\
\hline H33 & 118 & 146 & 1.24 \\
\hline H36 & 118 & 148 & 1.25 \\
\hline H43 & 117 & 154 & 1.32 \\
\hline H46 & 117 & 147 & 1.26 \\
\hline H49 & 117 & 147 & 1.26 \\
\hline
\end{tabular}

\section{1 이송속도 (Feed rate) 및 가공횟수}

Table 2는 실험 $\mathrm{F} 1$ 즉, 이송속도 $\mathrm{f}(\mathrm{mm} / \mathrm{rev})$ 가 0.0125 일 때, 12 개의 가공홀 입구에서 훼손된 영역에 대하여 처리된 이 미지로부터 얻어진 지름에 대한 픽셀개수와 계산된 박리 지수 값을 보여주고 있다. 그리고, Fig. 5는 가공홀 입구에 서 6단계별 이송속도(F1 F6) 조건에 대하여 계산된 박리지 수 값들을 그래프로 보여주고 있다.

우선, 전체적으로 이송속도가 증가할 수록 박리지수는 뚜렷하게 감소하는 경향을 보인다. 이러한 결과는 2 장에서 이미 설명한 것처럼 본 논문에서는 가공물을 고정구 및 지 지대로 충분히 고정한 상태에서 가공이 이루어졌으므로, 진동의 영향이 최소화된 상태에서 드릴의 이송속도가 빠 를수록 홀 입구 및 출구에서 박리현상이 적게 발생하는 것 에 기인한 것으로 볼 수 있다.

또한, 이송속도 각 단계별 하나의 시편에서 가공횟수가 증가할수록 박리지수가 모두 증가함을 보이고 있는데, 이 것은 가공이 진행될수록 드릴 마모로 인하여 박리영역이

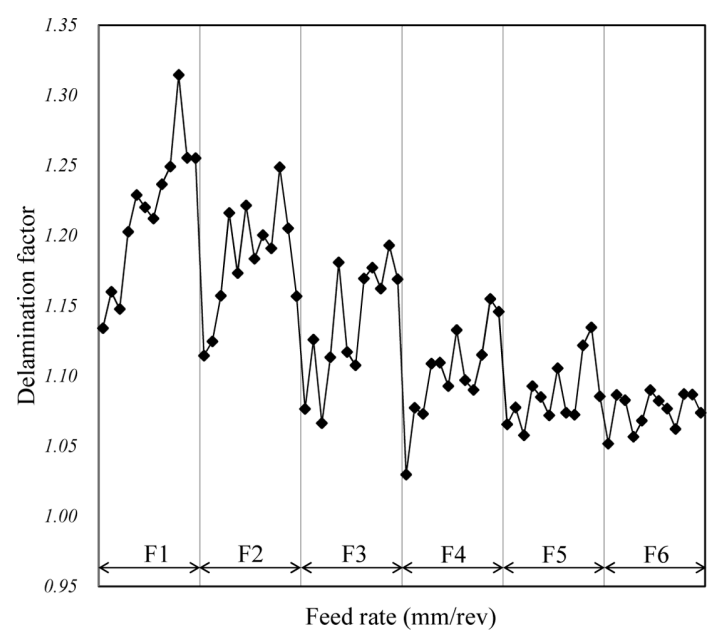

Fig. 5. Delamination factor by feed rate variation at entry hole

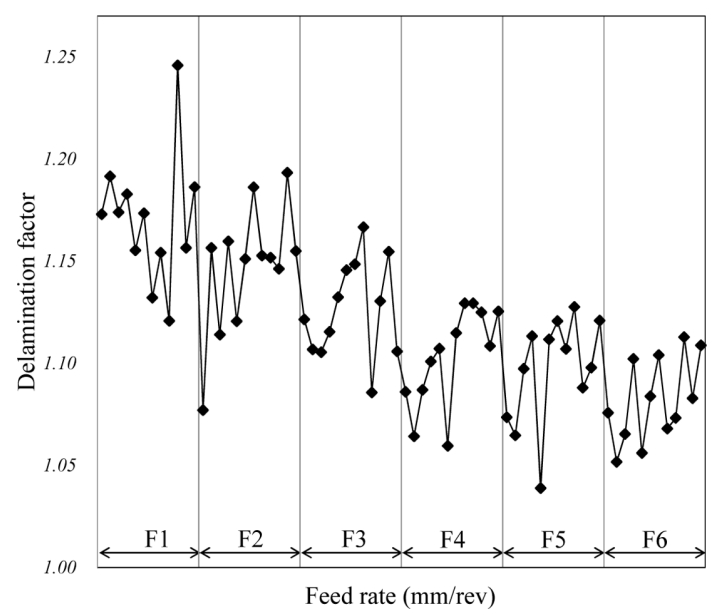

Fig. 6. Delamination factor by feed rate variation at exit hole

증가하기 때문인 것으로 분석된다. Fig. 6은 가공홀 출구에 서 이송속도 변화에 따라 얻어진 박리지수 결과값의 분포 를 보여주고 있다. 각 이송속도 단계별 박리지수 분포는 홀 입구의 경우와 거의 유사하고, 박리지수 값의 범위도 입구 와 큰 차이가 없다. 이것은 하나의 홀에서 가공이 진행될 때 입구와 비교하여 출구에서의 드릴공구 마모가 박리지수에 변화를 야기할 만큼 영향을 미치지 못하는 결과에 기인하 며, 시편 하부에 지지대를 전체적으로 부착시켜 가공함으 로써 가공상태가 홀입구와 유사하기 때문인 것으로 분석된다.

\section{2 절삭속도(Cutting speed)}

Fig. 7은 가공홀 입구에서 5 단계별 절삭속도(V1 V5) 조 건에 대하여 계산된 박리지수 값들을 그래프로 보여주고 있다. 전체적으로 절삭속도 변화에 대한 영향은 이송속도 변화의 영향과 비교하여 뚜렷하지는 않으나 절삭속도가 증 가함에 따라 박리지수는 감소함을 보이고 있다. 이것은 절 삭속도가 빠를수록 야기될 수 있는 훼손 면적이 줄어드는 


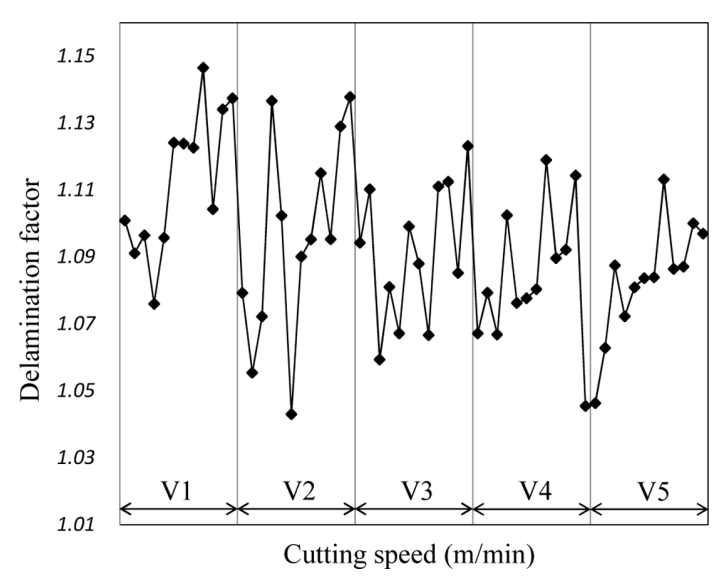

Fig. 7. Delamination factor by cutting speed variation at entry hole

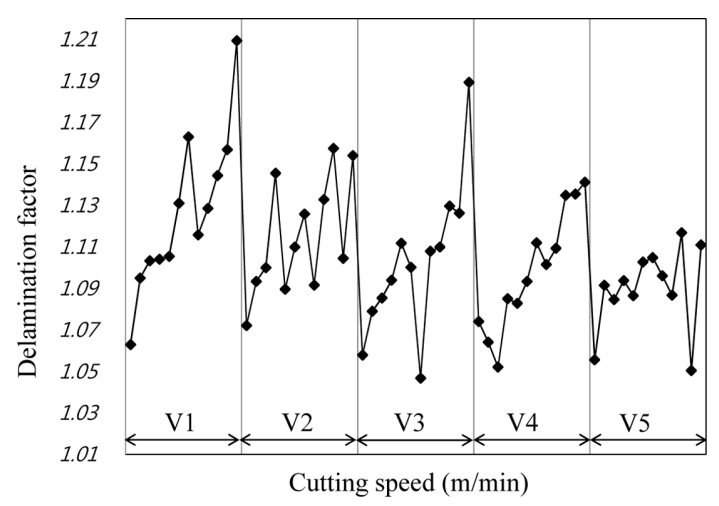

Fig. 8. Delamination factor by cutting speed variation at exit hole

현상 때문인 것으로 파악된다. 또한 하나의 절삭속도 조건 에서 가공횟수가 증가함에 따라 박리지수들이 증가함을 보 이고 있다. 이것은 이송속도 변화에 대한 결과와 비슷하며, 원인 또한 동일하다고 볼 수 있다. Fig. 8은 홀출구에서 산 출된 결과를 보여주고 있는데 절삭속도가 증가함에 따라 박리지수는 점차 감소함을 보여준다. 또한, 전체적으로 홀 입구에서 절삭속도 변화의 특성과 비교하여 비슷한 경향 을 가지며, 이것 역시 이송속도 변화의 경우와 유사하게 하 나의 홀 가공 동안 드릴 마모가 미치는 영향은 상대적으로 미미하며, 시편 하부의 지지대에 의하여 가공상태가 홀 입 구와 유사하기 때문이다.

\section{3 표면조도(Shape roughness)}

Table 3은 드릴 기준절삭속도 $\mathrm{Vc}=30.16$ 에서 이송속도 $\mathrm{f}(\mathrm{mm} / \mathrm{rev})$ 가 각각 $0.05,0.15,0.25$ 로 가공된 3 개의 유리섬유 복합재 플레이트에 총 50 개의 홀을 가공하여 각각 $1,25,50$ 번째 홀에서 측정한 6점 평균표면조도값을 보여주고 있다. 이송속도 값이 작을수록 평균표면조도값 $\left(\mathrm{R}_{\mathrm{a}}\right)$ 이 감소하는 데, 이것은 이송속도가 느릴수록 수직방향의 플라이 사이
Table 3. Measured surface roughness (im) by feed rate variation

\begin{tabular}{|c|c|c|c|c|c|c|c|c|}
\hline \multirow{2}{*}{$\begin{array}{c}\text { Part } \\
\text { (Hole\#) }\end{array}$} & \multicolumn{6}{|c|}{ Measured points } & \multirow{2}{*}{$\begin{array}{l}\text { Hole } \\
\text { Ave. }\end{array}$} & \multirow{2}{*}{$\begin{array}{l}\text { Part } \\
\text { Ave. }\end{array}$} \\
\hline & 1 & 2 & 3 & 4 & 5 & 6 & & \\
\hline $\mathrm{P} 1(\mathrm{H} 1)$ & 0.73 & 3.01 & 0.61 & 1.80 & 2.66 & 1.06 & 1.64 & \multirow{3}{*}{2.03} \\
\hline $\mathrm{P} 1(\mathrm{H} 25)$ & 2.36 & 1.36 & 2.34 & 1.37 & 3.15 & 1.67 & 2.04 & \\
\hline P1(H50) & 1.80 & 2.60 & 1.66 & 3.00 & 1.68 & 3.70 & 2.41 & \\
\hline $\mathrm{P} 2(\mathrm{H} 1)$ & 1.32 & 2.41 & 2.75 & 2.15 & 2.13 & 2.90 & 2.28 & \multirow{3}{*}{2.33} \\
\hline $\mathrm{P} 2(\mathrm{H} 25)$ & 0.71 & 2.60 & 2.40 & 1.81 & 3.50 & 2.25 & 2.23 & \\
\hline $\mathrm{P} 2(\mathrm{H} 50)$ & 2.80 & 1.86 & 2.75 & 3.86 & 2.30 & 1.64 & 2.50 & \\
\hline $\mathrm{P} 3(\mathrm{H} 1)$ & 2.40 & 2.52 & 1.75 & 3.40 & 2.20 & 3.45 & 2.62 & \multirow{3}{*}{2.53} \\
\hline $\mathrm{P} 3(\mathrm{H} 25)$ & 2.00 & 2.50 & 2.60 & 2.55 & 3.35 & 2.40 & 2.57 & \\
\hline P3(H50) & 1.62 & 2.06 & 2.85 & 3.35 & 1.95 & 2.60 & 2.41 & \\
\hline
\end{tabular}

Table 4. Surface roughness by cutting speed variation

\begin{tabular}{c|c|c|c|c|c|c}
\hline $\begin{array}{c}\text { Cutting } \\
\text { speed } \\
(\mathrm{m} / \mathrm{min})\end{array}$ & 10.66 & 15.08 & 21.31 & 30.16 & 41.65 & 60.32 \\
\hline $\begin{array}{c}\text { Surface } \\
\text { roughness } \\
(\mathrm{mm})\end{array}$ & 2.93 & 2.73 & 2.38 & 2.79 & 2.35 & 2.12 \\
\hline
\end{tabular}

의 기지(Matrix)의 레진(Resin)이 드릴 진행방향으로 흘러 내려 수평방향으로 가공된 플라이의 일부를 코팅하는 효 과에 의한 것으로 사료된다. 그리고 하나의 이송속도에서 가공횟수가 늘어날수록 표면조도값의 증감에 대한 경향성 은 뚜렷하지 않음을 알 수 있는데, 이것은 가공이 진행될수 록 공구마모 증가에 따른 가공면의 거칠기 증가와 레진의 밀림현상이 혼재함에 기인한 것으로 판단된다.

Table 4 는 이송속도 0.10 에서 절삭속도 변화에 따른 측정 된 표면조도값을 보여주고 있으며, 드릴속도 변화에 따른 표면조도의 경향성은 현저하지 않음을 알 수 있다. 이러한 드릴가공조건 변화에 대한 표면조도 특성은 탄소섬유(CFRP) 대한 이전 연구의 결과와 유사한 특징을 가짐을 볼 수 있다[6].

\section{4. 결 론}

본 논문에서는 유리섬유 복합재 드릴가공에서 가공조건 변화에 대하여 홀 입구 및 출구의 박리지수 상관관계와 홀 내부의 표면조도 영향을 비교하고 분석하였다. 박리지수 계산 정확도를 높이기 위하여 확대된 디지털 이미지로부 터 픽셀개수를 이용하여 최대박리지름을 구할 수 있는 새 로운 박리지수 관계식을 유도 및 적용하였다. 또한, 복합재 시편을 제작하여 진동 및 열 영향을 최소화할 수 있는 가공 조건에서 각 실험조건에 따라 드릴가공을 수행하였고, 박 리지수는 유도된 식을 적용하여 산출하였으며, 표면조도측 정은 정확도를 높이기 위하여 6점평균표면조도측정 방식 을 적용하였다. 실험 및 적용결과로부터, 박리지수는 드릴 
이송속도가 증가할수록 감소하며, 절삭속도가 증가함에 따 라 역시 다소 감소하는 특성이 관찰되고 분석되었다. 또한, 모든 가공조건에서 가공횟수에 비례하여 박리지수는 대폭 증가하는 특성을 가짐을 알 수 있었다. 또한 가공홀 내부의 표면조도는 이송속도가 증가함에 따라 증가하고, 절삭속도 변화에는 뚜렷한 경향성이 없는 것으로 파악되었다. 본 논 문의 결과를 이용하여 유리섬유복합재의 드릴가공조건을 보다 합리적으로 결정할 수 있을 것으로 사료된다.

\section{후 기}

본 연구는 2012년 정부(교육과학기술부) 재원 한국연구 재단의 대학중점연구소 지원 사업(2012-048078) 및 산업통 상자원부, 한국산업기술진흥원, 동남지역사업평가원의 광 역경제권 선도산업육성사업의 지원으로 수행된 연구결과 입니다.

\section{참고문헌}

1. Mallick, P.K., Fiber-Reinforced Composites Materials, Manufac- turing and Design, Marcel Dekker, Inc., U.S., 1988.

2. Hocheg, H., and Tsao, C., "The Path Towards Delamination Free Drilling of Composite Materials," Journal of Materials Processing Technology. Vol. 167, No. 2-3, 2005, pp. 251-264.

3. Chen, W.C., "Some Experimental Investigations in the Drilling of Carbon Fiber Reinforced Composite Laminations," International Journal of Machine Toll and Manufacture. Vol. 37, No. 8, 1997, pp. 1097-1108.

4. Mohan, N.S., Kulkarni, S.M., and Ramachandra, A., "Delamination Analysis in Drilling Process of Glass Fiber Reinforced Plastics (GFRP) Composite Materials," Journal of Materials Processing Technology. Vol. 186, No. 1-3, 2007, pp. 265-271.

5. Ramesh, B., Sharan, J.C., and Kavialagan, R., "Experimental Investigation and Optimization in Drilling GFRP Polymeric Composites Using Taguchi and Anova," International Journal of Mechanical and Production Engineering. Vol. 2, No. 1, 2013, pp. 52-60.

6. Zitoune, R., Krishnaraj, V., and Collombet, F., "Study of Drilling of Composite Material and Aluminium Stack," Composite Structures. Vol. 92, No. 5, 2010, pp. 1246-1255. 